Tropical Convective Responses to Microphysical and Radiative Processes:

\author{
A Sensitivity Study With a 2D Cloud Resolving Model \\ Xiaofan $\mathrm{Li}^{1}$ \\ Joint Center for Satellite Data Assimilation and \\ NOAA/NESDIS/Office of Research and Applications \\ Camp Springs, Maryland, USA \\ C.-H. Sui \\ Institute of Hydrological Sciences, National Central University \\ Chung-Li, Taiwan \\ K.-M. Lau, W.-K. Tao \\ NASA/GSFC/Laboratory for Atmospheres \\ Greenbelt, Maryland, USA
}

Submitted to Meteorology and Atmospheric Physics in July, 2003

Revised in November, 2003

Revised and accepted in March, 2004

\footnotetext{
${ }^{1}$ Corresponding author address: Xiaofan Li, NOAANESDIS/ORA, 5200 Auth Road, Room 711, Camp Springs, MD 20746, USA

E-mail: Xiaofan.Li@noaa.gov
} 


\begin{abstract}
Prognostic cloud schemes are increasingly used in weather and climate models in order to better treat cloud-radiation processes. Simplifications are often made in such schemes for computational efficiency, like the scheme being used in the National Centers for Environment Prediction models that excludes some microphysical processes and precipitation-radiation interaction. In this study, sensitivity tests with a $2 \mathrm{D}$ cloud resolving model are carried out to examine effects of the excluded microphysical processes and precipitation-radiation interaction on tropical thermodynamics and cloud properties. The model is integrated for 10 days with the imposed vertical velocity derived from the Tropical Ocean Global Atmosphere Coupled Ocean-Atmosphere Response Experiment. The experiment excluding the depositional growth of snow from cloud ice shows anomalous growth of cloud ice and more than $20 \%$ increase of fractional cloud cover, indicating that the lack of the depositional snow growth causes unrealistically large mixing ratio of cloud ice. The experiment excluding the precipitation-radiation interaction displays a significant cooling and drying bias. The analysis of heat and moisture budgets shows that the simulation without the interaction produces more stable upper troposphere and more unstable mid and lower troposphere than does the simulation with the interaction. Thus, the suppressed growth of ice clouds in upper troposphere and stronger radiative cooling in mid and lower troposphere are responsible for the cooling bias, and less evaporation of rain associated with the large-scale subsidence induces the drying in mid and lower troposphere.
\end{abstract}




\section{Introduction}

Clouds microphysical processes and cloud-radiation interaction play an important role in tropical weather and climate. Convective processes, which generate precipitation, cannot be resolved in general circulation models (GCMs). To meet the needs of the models, various cumulus parameterization schemes have been designed to estimate the amount of the precipitation and the associated heating and moistening effects using the large-scale variables in the GCMs. The most commonly used cumulus parameterization schemes in the GCMs have led to many successes in the simulation of atmospheric circulations. However, most of the schemes calculate precipitation diagnostically and do not allow an explicit representation of clouds and the cloud-radiation interaction in the GCMs.

Sundquist (1978) and Sundqvist et al. (1989) first developed a prognostic cloud scheme for cloud water. The scheme allows an explicit representation of nonprecipitating water clouds and the exchange of cloud water among the columns. They showed that the large-scale and mesoscale models with the scheme yield reasonable time evolution of cloud water and precipitation amounts. The prognostic cloud schemes have been applied to the GCM and regional models that led to improvement of numerical weather prediction in global and regional scales (e.g., Golding, 1990; Smith, 1990; Pudykiewicz et al., 1992; Tiedtke, 1993; Mannoji, 1995; Willoughby et al., 1984; Lord et al., 1984; Liu et al., 1997; Zhao and Carr, 1997).

Among the many studies discussed above, Zhao and Carr (1997), hereafter referred to as ZC97, developed a prognostic cloud scheme with the diagnostic precipitation for operational numerical weather prediction models. The scheme includes 
prognostic equations for non-precipitating water and ice clouds and sophisticated microphysical processes associated with the growth of clouds and generation of precipitation. They showed that the inclusion of ice clouds in the models is important in transferring water vapor to precipitation and in the enhancement of latent heat release, which is consistent with the results by Willoughby et al. (1984), Lord et al. (1984), and Liu et al. (1997) that the inclusion of ice microphysics parameterization schemes in the models led to more realistic simulation of cloud structures of model hurricanes. The scheme has been used in the operational Global Data Assimilation Systerm (GDAS) at National Oceanic and Atmospheric Administration (NOAA)/National Centers for Environmental Prediction (NCEP), USA. Since it is designed as a computational efficient scheme for operational models, ZC97 excludes some microphysical processes and calculates precipitation diagnostically without the physical presence of corresponding hydrometeors, which is equivalent to exclude precipitation-radiation interaction.

In this study, tropical convective responses to microphysical and radiative processes are investigated with a $2 \mathrm{D}$ cloud resolving model to examine the possible effects of the microphysical processes and precipitation-radiation interaction on tropical thermodynamics and cloud properties excluded by ZC97. Concerning the fact that the ZC97 scheme and the bulk cloud microphysics scheme are not the same, and that the two schemes are applied to different models, the current study is more a sensitivity test rather than an evaluation of the effect of certain neglected microphysical processes. In section 2 , the model forcing, and experiment designs will be discussed. In section 3, the model sensitivity tests and the comparison between the satellite-retrieved cloud products and GDAS data are carried out to show that the exclusion of the microphysical processes by 
ZC97 in the model physics may simulate unrealistically large mixing ratio of cloud ice. The cause of the unrealistic simulation of cloud ice is further examined analyzing the budget of cloud ice in the cloud resolving simulations. In section 4 , effects of precipitation-radiation interaction on the tropical thermodynamics are examined using the cloud resolving simulations. The summary is given in section 5 .

\section{Model and experiments}

The cloud resolving model was originally developed by Soong and Ogura (1980), Soong and Tao (1980), and Tao and Simpson (1993). The 2D version of the model used by Sui et al. $(1994,1998)$ and further modified by Li et al. (1999) is used in this study. The governing equations and model setup can be found in Li et al. $(1999,2002 \mathrm{c})$. Several $2 \mathrm{D}$ cloud resolving models have successfully simulated atmospheric thermodynamic profiles, cloud properties, and precipitation in the tropics during the Global Atmospheric Research Program Atlantic Tropical Experiment (GATE) (e.g., Xu and Randall; 1996; Grabowski et al., 1996; 1998; 1999) and Tropical Ocean Global Atmosphere Coupled Ocean-Atmosphere Response Experiment (TOGA COARE) (e.g., Wu et al., 1998; 1999; Li et al., 1999; 2002a;b;c; Johnson et al., 2004). It should be pointed out that the highfrequency temporal variability with spatial distributions such as individual cloud and associated dynamic and thermodynamic patterns might be distorted due to the $2 \mathrm{D}$ model setup. However, Grabowski et al. (1998) compared 3D and 2D simulations and showed the similar evolution in their thermodynamic fields, surface heat fluxes, and surface precipitation.

For zonal mean heat budget as shown in Li et al. (1999), 


$$
\frac{\partial \bar{T}}{\partial t}=\frac{\bar{Q}_{c n}}{c_{p}}+\frac{\bar{Q}_{R}}{c_{p}}-\frac{\pi}{\bar{\rho}} \frac{\partial\left(\bar{\rho} w^{\prime} \theta^{\prime}\right)}{\partial z}-\pi \bar{w}^{0} \frac{\partial \bar{\theta}}{\partial z}-\bar{u}^{\circ} \frac{\partial \bar{T}^{\circ}}{\partial x}
$$

Thus, the local change of zonal mean temperature is contributed by condensational heating, radiative heating, convergence of vertical heat flux, vertical temperature advection, and imposed horizontal temperature advection.

For zonal mean moisture budget,

$$
\frac{\partial \bar{q}_{\nu}}{\partial t}=-\bar{S}_{q v}-\frac{1}{\bar{\rho}} \frac{\partial\left(\bar{\rho} \overline{w_{q_{\nu}^{\prime}}^{\prime}}\right)}{\partial z}-\bar{w}^{o} \frac{\partial \bar{q}_{v}}{\partial z}-\bar{u}^{o} \frac{\partial \bar{q}_{\nu}^{o}}{\partial x}
$$

Thus, the local change of zonal mean water vapor is contributed by net condensation, convergence of vertical moisture flux, vertical moisture advection, and imposed horizontal moisture advection.

The model is forced by the zonally uniform vertical velocity, zonal wind, and thermal and moisture advections, which are derived by Professor M. Thang and his research group at the State University of New York at Stony Brook, based on the 6hourly TOGA COARE observations within the Intensive Flux Array (IFA) region (Zhang, personal communication, 1999). The calculations are based on the constrained variational method on column-integrated budgets of mass, heat, moisture and momentum proposed by Zhang and Lin (1997). Hourly sea surface temperature at the Improved Meteorological (IMET) surface mooring buoy $\left(1.75^{\circ} \mathrm{S}, 156^{\circ} \mathrm{E}\right)$ (Weller and Anderson, 1996 ) is also imposed in the model. The model is integrated from 0400 LST 19 December 1992, to 0400 LST 29 December 1992 (10 days total). Figure 1 shows the time evolution of vertical distribution of the large-scale atmospheric vertical velocity, zonal wind, and the time series of the sea surface temperature (SST) during the 10-day period. In this model setup, the horizontal boundary is periodic. The horizontal domain is 768 
$\mathrm{km}$, and the horizontal grid mesh is $1.5 \mathrm{~km}$. The vertical grid resolution ranges from about $200 \mathrm{~m}$ near the surface to about $1 \mathrm{~km}$ about $100 \mathrm{mb}$. The time step is $12 \mathrm{~s}$.

The control experiment $\mathrm{C}$ uses hydrometeor equations (A1)-(A5) in the appendix, consisting of the full set of microphysical schemes used in the cloud resolving model. To test the impacts of the excluded microphysical processes in ZC97, we first identify the 14 microphysical processes (the italicized terms in Fig. A1) being excluded by ZC97 in terms of microphysical schemes used in the cloud resolving model. A complete description of the terms can be found in the appendix (also see Li et al., 1999; 2002c). Then, the second experiment, C14, is carried out using (A10)-(A13) in which the 14 microphysical terms are excluded. Note that (A10)-(A13) is derived for C14 that is symbolically similar to those used in ZC97, actually separate prognostic equations for the five hydrometeor species are still used in the simulation.

We carry out the third experiment, CSFI, which is the same as C14 except for the inclusion of the $\mathrm{P}_{\mathrm{SFI}}\left(\mathrm{T}<\mathrm{T}_{\mathrm{o}}\right.$ ). Thus, the CSFI uses (A10)-(A13) except that (A13b) is changed to $P_{s g}=P_{S A U T}\left(T<T_{o}\right)+P_{S A C I}\left(T<T_{o}\right)+P_{S F I}\left(T<T_{o}\right)$.

The $\mathrm{P}_{\mathrm{SFI}}$ is the main process to consume cloud ice in the growth of snow. Hsie et al. (1980) modified the work of Orville and Kopp (1977) that was based on the equation of the rate of growth of ice crystals by deposition proposed by Koenig (1971), and formulated $\mathrm{P}_{\mathrm{SFI}}$ by the mixing ratio divided the timescale that is needed for an ice crystal to grow from radius $40 \mu \mathrm{m}$ to radius $50 \mu \mathrm{m}$. Based on the aircraft observations, Krueger et al. (1995) suggested that the timescale in $\mathrm{P}_{\mathrm{SFI}}$ should be for a crystal to grow from $40 \mu \mathrm{m}$ to radius $100 \mu \mathrm{m}$, which increases mixing ratio of cloud ice as indicated in Li et al. 
(1999). In this study, modified formulation of $P_{\mathrm{SF}}$ by Krueger et al. (1995) is used. Krueger et al. (1995) called $\mathrm{P}_{\mathrm{SFI}}$ as the snow formation associated with the Bergeron process (snow production from cloud ice via the growth of Bergeron-process embryos). However, Bergeron (Bergeron-Findeisen) process is the diffusional growth of ice crystals in the presence of supercooled water droplets. Therefore, the $P_{\mathrm{SFI}}$ is defined in this study as the depositional growth of snow from cloud ice.

ZC97 calculated precipitation diagnostically based on the assumption that the precipitation water $\left(\mathrm{q}_{\mathrm{r}}\right)$ and ice $\left(\mathrm{q}_{\mathrm{s}}\right.$ and $\left.\mathrm{q}_{\mathrm{g}}\right)$ fall out of clouds to ground immediately. A major effect being neglected by this assumption is the interaction of precipitating particles with radiation. To examine the impacts of the precipitation-radiation interaction on tropical thermodynamics and cloud properties, the fourth experiment $\mathrm{CN}$ is carried out. The difference between the $\mathrm{CN}$ and $\mathrm{C}$ is that the $\mathrm{CN}$ excludes the precipitationradiation interaction by simply setting zero mixing ratios of precipitation water and ice when the radiation is calculated.

\section{Important sink of cloud ice: depositional growth of snow}

We first examine the differences between experiments $\mathrm{C}$ and $\mathrm{C} 14$. Figure 2 shows the time series of surface rain rate and vertically integrated mass-weighted mixing ratios of cloud water ([qc]) and cloud ice ([qi]). The surface rain rates in the two experiments have similar temporal evolution because of the same imposed vertical velocity. However, [qc] and [qi] are much larger in C14 than in C, in particular, [qi] in C14 is more than one order of magnitude larger than in C (note the different plotting scales of [qi] for $\mathrm{C} 14$ and C in Fig. 2c). 
Since C14 has similar microphysical schemes as does ZC97, we wonder whether ZC97 has the same tendency to produce unrealistically large mixing ratio of cloud ice. However, the observational and GDAS data are not available during the TOGA COARE. Thus, we proceed to compare the ice water path (TWP: mass-integrated mixing ratio of ice clouds including cloud ice, snow and graupel) and liquid water path (LWP: massintegrated mixing ratio of water clouds including cloud water and raindrops) simulated by the GDAS with those retrieved by NOAANational Environmental Satellite, Data, Information Service (NESDIS)/Microwave Surface and Precipitation Products System (MSPPS) using the data from Advanced Microwave Sounder Unit (AMSU) onboard NOAA-15, 16, and 17 in recent years. The LWP and IWP are retrieved using two AMSU-A window channels at 23.8 and $31.4 \mathrm{GHz}$ (Weng et al., 1997; 2003) and two AMSU-B channels at 89 and $150 \mathrm{GHz}$ (Weng and Grody, 2000; Weng et al., 2003), respectively. The horizontal resolution of the data used here is $50 \mathrm{~km}$.

Figure 3 shows the IWP versus LWP using the MSPPS and GDAS data over global oceanic tropics between $5^{\circ} \mathrm{S}$ and $5^{\circ} \mathrm{N}$ on March 2003. The IWP simulated by the GDAS has the similar magnitudes to that observed in the MSPPS data ( $2 \mathrm{~mm}$ ) whereas the LWP in the MSPPS data ( $3 \mathrm{~mm}$ ) is three times as large as the GDAS simulated LWP $(1 \mathrm{~mm})$. Since the IWP and LWP shown in Fig. 3a include both non-precipitating ice and water and precipitating ice and water whereas those shown in Fig. $3 \mathrm{~b}$ include nonprecipitation ice and water (cloud ice and cloud water) only, the comparison may suggest that the GDAS simulates the unrealistically large mixing ratio of ice clouds by using ZC97. Figures 2 and 3 also show that the cloud resolving model may simulate larger IWP and IWP in comparison with MSPPS observations. 
The anomalous [qi] causes a large cooling above the ice clouds due to the reflection of the solar radiation and a large warming below due to the energy trapping of the longwave radiation, and positive difference of water vapor fields between $\mathrm{C} 14$ and $\mathrm{C}$ (Fig. 4). Table 1 also shows that 10-day mean fractional covers of raining convective, räining stratiform, non-raining stratiform clouds in $\mathrm{C} 14(\mathrm{C})$ are about $7.1 \%, 15.6 \%$, and $65.6 \%,(4.8 \%, 12.8 \%$, and $52.4 \%)$ respectively. The result indicates a respective increase of $48 \%, 22 \%$, and $25 \%$ in the fractional covers of raining convective, raining stratiform, non-raining stratiform clouds from $\mathrm{C}$ to $\mathrm{C} 14$. The $\mathrm{C} 14$ confirms unrealistic simulation of cloud ice. The budgets of [qi] in C and C14 are then analyzed to identify the cause of the unrealistic [qi] simulation in C14.

The time series of vertically integrated budgets of [qi] (Eq. A3) in C and C14 is shown, respectively, in Fig. $5 \mathrm{a}$ and $5 \mathrm{~b}$. In C, the growth rate of [qi] by the vapor deposition ([ $\left.\left.\mathrm{P}_{\mathrm{DEP}}\right]\right)$ is nearly balanced by the growth rate of snow by the conversion of cloud ice $\left(\left[\mathrm{P}_{\mathrm{SAUT}}\right]\right)$ as well as by $\left[\mathrm{P}_{\mathrm{SFI}}\right]$ (Fig. 5a). Thus, the sum of the rates responsible for the growth of [qi] ([Sqi]) is very small. [P $\left.\mathrm{P}_{\mathrm{SFI}}\right]$ is smaller than $\left[\mathrm{P}_{\mathrm{SAUT}}\right]$, but it is important sink of cloud ice. In the first five days of the integration of $\mathrm{Cl} 4,\left[\mathrm{P}_{\mathrm{DEP}}\right]$ and $\left[\mathrm{P}_{\mathrm{SAUT}}\right]$ cancel in large part, but there is a considerable magnitude of [Sqi] contributed by homogeneous freezing of cloud water $\left(\left[\mathrm{P}_{\text {HОM }}\right]\right)$, which leads to the initial anomalous growth of cloud ice (Fig. 5b). The rapid decrease of the magnitude of $\left[\mathrm{P}_{\text {SAUT }}\right]$ cannot offset $\left[\mathrm{P}_{\mathrm{DEP}}\right]$ so that large $[\mathrm{Sqi}]$ is responsible for the rapid increase of [qi] in late evening of 24 December and early morning of 25 December (also see Fig. 3c). In the second five days of the integration, $\left[\mathrm{P}_{\mathrm{HHOM}}\right]$ and $\left[\mathrm{P}_{\mathrm{SACl}}\right]$ (the collection of cloud ice by snow) become as important as $\left[\mathrm{P}_{\mathrm{DEP}}\right]$ and $\left[\mathrm{P}_{\mathrm{SAUT}}\right]$ in the budget of [qi]. A comparison of budgets of [qi] 
between $\mathrm{C}$ and $\mathrm{C} 14$ indicates that $\left[\mathrm{P}_{\mathrm{SFI}}\right]$ is important sink of cloud ice in $\mathrm{C}$, but it is excluded in C14, which may be the cause of anomalous growth of cloud ice in C14. Thus, $\mathrm{P}_{\text {SFI }}$ is included in the additional experiment CSFI that is conducted to further examine the cause of the difference between C14 and C.

The temperature differences in the upper troposphere are significantly reduced in CSFI $-\mathrm{C}$ (Fig. 6a) compared to those in $\mathrm{Cl} 4-\mathrm{C}$ (Fig. 4a). Also notice that the positive and negative temperature differences appear alternatively (Fig. 6a). The differences of water vapor exhibit a slightly positive trend with the most of the positive differences of less than $1 \mathrm{gkg}^{-1}$ (Fig. 6b). The fractional cloud covers in CSFI also display significant reduction from $\mathrm{C} 14$ and their 10-day mean values in CSFI become similar to those in C (Table 1). Thus, The CSFI confirms the crucial role of $P_{\text {SFI }}$ as the sink of [qi] in the balance of cloud ice. The results suggest that the budget of cloud ice be carefully treated to avoid unrealistic cloud calculations.

Finally, 10-day mean vertically integrated cloud microphysics budgets in $\mathrm{C}$ and CSFI (Fig. 7) are compared. As shown in Li et al. (2002c), most of the conversion of cloud water to precipitation in C occurs primarily by the collection of cloud water by raindrops $\left(\left[\mathrm{P}_{\mathrm{RACW}}\right]=0.405 \mathrm{mmh}^{-1}\right)$ at the temperature warmer than $0^{\circ} \mathrm{C}$ and by the riming of cloud water onto precipitation ice (snow and graupel) $\left(\left[\mathrm{P}_{\mathrm{GACW}}\right]+\left[\mathrm{P}_{\mathrm{SACW}}\right]=0.157 \mathrm{mmh}^{-}\right.$ ) at colder temperatures. Because the growth of precipitation ice through the conversion from cloud water is not allowed in CSFI, most of the conversion of cloud water to precipitation occurs primarily by the collection of cloud water by raindrops $\left(\left[\mathrm{P}_{\mathrm{RACW}}\right]=0.56 \mathrm{mmh}^{-1}\right)$ at the temperature warmer than $0^{\circ} \mathrm{C}$. This leads to smaller mixing ratio of graupel in CSFI $(0.07 \mathrm{~mm})$ than in C $(0.11 \mathrm{~mm})$. In the budget of [qr], the 
evaporation of raindrops $\left(\left[\mathrm{P}_{\mathrm{REVP}}\right]=0.289 \mathrm{mmh}^{-1}\right)$ is nearly compensated by the melting of graupel $\left(\left[\mathrm{P}_{\mathrm{GMLT}}\right]=0.308 \mathrm{mmh}^{-1}\right)$ so that the collection of cloud water by raindrops $\left(\left[P_{R A C W}\right]=0.405 \mathrm{mmb}^{-1}\right)$ accounts mainly for surface rain rate $\left(0.476 \mathrm{mmh}^{-1}\right)$ in $\mathrm{C}$. In $\mathrm{CSFI}$, only half of $\left[\mathrm{P}_{\mathrm{REVP}}\right]\left(0.296 \mathrm{mmh}^{-1}\right)$ is compensated by $\left[\mathrm{P}_{\mathrm{GMLT}}\right]\left(0.153 \mathrm{mmh}^{-1}\right)$. In the budget of [qi], the vapor deposition rate in CSFI $\left(\left[\mathrm{P}_{\mathrm{DEP}}\right]=0.173 \mathrm{mmh}^{-1}\right)$ is larger than in $\mathrm{C}\left(0.124 \mathrm{mmh}^{-1}\right)$. The rates of $\left[\mathrm{P}_{\mathrm{SAUT}}\right]$, $\left[\mathrm{P}_{\mathrm{SFI}}\right]$, and $\left[\mathrm{P}_{\mathrm{SACI}}\right]$ in $\operatorname{CSFI}(0.126,0.049,0.006$ $\left.\mathrm{mmh}^{-1}\right)$ are larger than in $\mathrm{C}\left(0.084,0.035,0.004 \mathrm{mmh}^{-1}\right)$, respectively. The larger conversion rates from [qi] to [qs] in CSFI maintain the similar amount of [qs] of C.

\section{Important impacts on thermodynamics: precipitation-radiation interaction}

As mentioned already, ZC97 does not have the prognostic variables for precipitation (rain and precipitation ice), which leads to exclude the interaction of precipitating clouds with radiation in the model calculations in the GDAS. The effect of such simplification is examined by comparing $\mathrm{CN}$ and $\mathrm{C}$. The comparison of 10-day mean fractional cloud covers between $\mathrm{CN}$ and $\mathrm{C}$ (Table 1) shows that the total fractional cloud covers in $\mathrm{CN}(71.5 \%)$ and $\mathrm{C}(70 \%)$ are slightly different. Then, a comparison study between $\mathrm{CN}$ and $\mathrm{C}$ is carried out to examine impacts of interaction between precipitation water and ice (raindrops, snow, and graupel) and radiation on atmospheric thermodynamics.

Figure 8a shows the temporal and vertical distribution of temperature differences between $\mathrm{CN}$ and $\mathrm{C}(\mathrm{CN}-\mathrm{C})$. Within the first three days of integration, the temperature differences are mostly positive except in late 21 December 1992 when negative temperature differences occur. From late 22 December 1992 on, the temperature 
differences below $200 \mathrm{mb}$ level become persistently negative with minimum values of $-1.5 \sim-2^{\circ} \mathrm{C}$. This indicates that the exclusion of precipitation-radiation interaction causes a cold bias in the troposphere. Li et al. (1999) carried out the comparison study between simulations and observations and showed that the simulated temperature in $\mathrm{C}$ is colder than the observed temperature in TOGA COARE (their Fig. 2a), the exclusion of the interaction processes in the simulation induces more cooling bias.

To examine the physical processes responsible for the temperature differences, we integrated each term of (8) with time for $\mathrm{CN}$ and $\mathrm{C}$ separately and then took the difference $(\mathrm{CN}-\mathrm{C})$ to obtain the corresponding temperature differences due to condensational heating, radiative heating, convergence of vertical heat flux, and vertical temperature advection, respectively (Figs. 8b-8e). Note that the imposed horizontal temperature advection has no contribution to the temperature differences. The temperature differences due to radiation are negative below $500 \mathrm{mb}$, and positive above, with the maximum and minimum values reaching $6^{\circ} \mathrm{C}$ around $325 \mathrm{mb}$ and $-6^{\circ} \mathrm{C}$ around $575 \mathrm{mb}$, respectively, at the end of the integrations (Fig. 8c). The radiation-induced differences in thermal stratification cause a more stable layer above $500 \mathrm{mb}$ in $\mathrm{CN}$ than in C. This corresponds to less ice hydrometeors in $\mathrm{CN}$ than in C (also see Fig. 9b), which lead to less latent heating above $500 \mathrm{mb}$ in $\mathrm{CN}$ from 23 December 1992 on (Fig. 8b). The temperature differences due to the convergence of vertical heat flux in Fig. $8 \mathrm{~d}$ show a banded structure with negative zones around $650-800 \mathrm{mb}$ and $550 \mathrm{mb}$ and mostly positive values elsewhere. The temperature differences due to vertical advection as shown in Fig. $8 \mathrm{e}$ are all negative except the 500-800 $\mathrm{mb}$ layer where positive values exist. Considering the contribution to the temperature difference of $\mathrm{CN}$ minus $\mathrm{C}$ by all 
terms, the negative temperature differences above $500 \mathrm{mb}$ level are mainly contributed by less cloud heating as a result of more stability in $\mathrm{CN}$, whereas more radiative cooling in $\mathrm{CN}$ is directly responsible for the negative temperature differences below $500 \mathrm{mb}$ level.

Next, we examine the temporal and vertical distribution of the difference fields of specific humidity (CN-C) in Fig. 9a, and the contribution to the moisture differences due to condensation, convergence of vertical moisture flux, and vertical moisture advection [see (9)] in Figs. 9b-d, respectively. The difference values of the water vapor mixing ratio are persistently negative below $500 \mathrm{mb}$ during the integrations, with minimum around -1 to $-1.5 \mathrm{gkg}^{-1}$. The significant drying begins on 23 December 1992. The exclusion of precipitation-radiation interaction in $\mathrm{CN}$ causes more unstable lower troposphere that leads to less evaporation of raindrops associated with subsidence that results in more drying, compared to $\mathrm{C}$ (Fig. 9b). Note that the imposed horizontal moisture advection has no contribution to the moisture differences. The contributions to vertical distributions of moisture differences by the other two terms, the convergence of vertical moisture flux and vertical moisture advection, largely cancel each other due to an out-of-phase relation (Figs. 9c, 9d). Thus, the less rain evaporation associated with large-scale subsidence as a result of more instability in the lower troposphere increases water vapor more slowly that leads to negative vapor differences. In summary, the comparison between $\mathrm{CN}$ and $\mathrm{C}$ indicates that exclusion of the interaction of precipitation with radiation in the simulations causes a significant cooling and drying bias in troposphere.

\section{Summary}


We carry out a sensitivity study to examine the effect of certain neglected microphysical processes in the prognostic cloud scheme proposed by Zhao and Carr (1997) that has been used in operational numerical weather prediction models. The ZC97 scheme excludes some microphysical processes and precipitation-radiation interaction for computational efficiency. Evaluating the effect of such simplifications in the large-scale models is not a simple task due to the interactions among different physical and dynamic processes. A lack of detailed microphysics measurements makes the task even more daunting. In this study, a cloud resolving model and relevant observations are used to examine the possible effects of the simplifications in the thermodynamic and cloud simulations.

The sensitivity tests are carried out with a $2 \mathrm{D}$ cloud resolving model. The cloud model is integrated for 10 days with the imposed large-scale vertical velocity, zonal wind, and large-scale horizontal thermal and moisture advection observed and derived from the Tropical Ocean Global Atmosphere Coupled Ocean-Atmosphere Response Experiment (TOGA COARE). The experiment with the prognostic cloud scheme excluding the depositional growth of snow from cloud ice shows that the mixing ratio of cloud ice grows rapidly, which leads to more than $20 \%$ increase of fractional cloud covers and unrealistic vertical stratification compared to the experiment with full cloud microphysical parameterization package, indicating that the exclusion of the depositional growth of snow from cloud ice in the simulation could cause anomalous growth of cloud ice. Such a unrealistically large cloud ice simulation is also found in the GDAS data when they are compared with the satellite-retrieved cloud products. 
The comparison between the experiments including and excluding precipitationradiation interaction shows that the exclusion of the interaction in the model causes a cooling and drying bias. A further analysis of heat budgets reveals that the experiment excluding the interaction exhibits a more stable upper troposphere (above $500 \mathrm{mb}$ ) and a more unstable lower troposphere (below $500 \mathrm{mb}$ ) relative to the experiment including the interaction. The more stable upper troposphere suppresses the development of ice clouds that is responsible for the cooling bias whereas the more radiative cooling accounts directly for cooling bias in mid and lower troposphere in the experiment excluding the interaction. The analysis of moisture budgets shows that the suppression of rain evaporation as a result of less stable mid and lower troposphere induces the drying bias when the model excludes the interaction process. It should be notice that the schemes used in the cloud resolving model are different from those used in ZC97 even if the same microphysical processes are included. Nevertheless, the study suggests that the depositional growth of snow from cloud ice and precipitating hydrometeor-radiation interaction be included in prognostic cloud schemes such as ZC97 for better prediction of atmospheric thermodynamics and cloud properties.

Acknowledgments. This research is supported by the Joint Center for Satellite Data Assimilation, TRMM project of NASA Earth Science Enterprise, and the National Central University by NSC grant 91-2621-Z-008-008. Authors thank M. Zhang at the State University of New York at Stony Brook for TOGA COARE forcing data, F. Weng and R. R. Ferraro at NOAA/NESDIS for MSPPS IWP/LWP data, Y. Zhu NOAA/NCEP/EMC for GDAS data, and two anonymous reviewers for their comments. 
The views, opinions, and findings contained in this report are those of the author(s) and should not be construed as an official National Oceanic and Atmospheric Administration or U.S. Government position, policy, or decision. 
Table 1 10-day mean fractional covers (\%) of raining convective (fcrcc), raining stratiform (fcrsc), non-raining stratiform (fcnrsc) clouds.

\begin{tabular}{|c|c|c|c|}
\hline Experiment & fcrcc & fcrsc & fcnrsc \\
\hline C & 4.8 & 12.8 & 52.4 \\
\hline C14 & 7.1 & 15.6 & 65.6 \\
\hline CSFI & 5.1 & 13.3 & 54.4 \\
\hline CN & 4.5 & 11.9 & 55.1 \\
\hline
\end{tabular}




\section{Appendix}

Prognostic Equations of Hydrometeors and Microphysical Processes Parameterized in the Cloud Resolving Model

The prognostic equations of hydrometeors in the cloud resolving model can be expressed as

$$
\begin{aligned}
& \frac{\partial q_{c}}{\partial t}=-\frac{\partial\left(u q_{c}\right)}{\partial x}-\frac{1}{\bar{\rho}} \frac{\partial\left(\bar{\rho} w q_{c}\right)}{\partial z}-P_{S A C W}-P_{R A U T}-P_{R A C W}-P_{S F W}\left(T<T_{o}\right)-P_{G A C W}+P_{C N D} \\
& -P_{I H O M}\left(T<T_{o o}\right)+P_{I M L T}\left(T>T_{o}\right)-P_{I D W}\left(T_{o o}<T<T_{o}\right) \\
& \frac{\partial q_{r}}{\partial t}=-\frac{\partial\left(u q_{r}\right)}{\partial x}-\frac{1}{\rho} \frac{\partial}{\partial z} \bar{\rho}\left(w-w_{T r}\right) q_{r}+P_{S A C W}\left(T>T_{o}\right)+P_{R A U T}+P_{R A C W}+P_{G A C W}\left(T>T_{o}\right) \\
& -P_{R E V P}+P_{R A C S}\left(T>T_{o}\right)-P_{L A C R}\left(T<T_{o}\right)-P_{G A C R}\left(T<T_{o}\right)-P_{S A C R}\left(T<T_{o}\right)-P_{G F R}\left(T<T_{o}\right) \\
& +P_{S M E T}\left(T>T_{o}\right)+P_{G M L T}\left(T>T_{o}\right) \\
& \frac{\partial q_{i}}{\partial t}=-\frac{\partial\left(u q_{i}\right)}{\partial x}-\frac{1}{\bar{\rho}} \frac{\partial\left(\rho w q_{i}\right)}{\partial z}-P_{S A U T}\left(T<T_{o}\right)-P_{S A C I}\left(T<T_{o}\right)-P_{R A C I}\left(T<T_{o}\right) \\
& -P_{S F I}\left(T<T_{o}\right)-P_{G A C T}\left(T<T_{o}\right)+P_{I H O M}\left(T<T_{o o}\right)-P_{I M L T}\left(T>T_{o}\right)+P_{D E P} \\
& +P_{I D W}\left(T_{o o}<T<T_{o}\right), \\
& \frac{\partial q_{s}}{\partial t}=-\frac{\partial\left(u q_{s}\right)}{\partial x}-\frac{1}{\bar{\rho}} \frac{\partial}{\partial z} \bar{\rho}\left(w-w_{T s}\right) q_{s}+P_{S A U T}\left(T<T_{o}\right)+P_{S A C I}\left(T<T_{o}\right)+\delta_{4} P_{S A C W}\left(T<T_{o}\right) \\
& +P_{S F W}\left(T<T_{o}\right)+P_{S F I}\left(T<T_{o}\right)+\delta_{3} P_{R A C I}\left(T<T_{o}\right)-P_{R A C S}\left(T>T_{o}\right)-P_{G A C S}-P_{S M L T}\left(T>T_{o}\right) \\
& -\left(1-\delta_{2}\right) P_{R A C S}\left(T<T_{o}\right)+\delta_{2} P_{S A C R}\left(T<T_{o}\right)+\left(1-\delta_{1}\right) P_{S D E P}\left(T<T_{o}\right)-P_{M A C T S}\left(T>T_{o}\right) \\
& +\delta_{3} P_{L A C R}\left(T<T_{o}\right)-\left(1-\delta_{4}\right) P_{W A C S}\left(T<T_{o}\right)
\end{aligned}
$$




$$
\begin{aligned}
& \frac{\partial q_{g}}{\partial t}=-\frac{\partial\left(u q_{g}\right)}{\partial x}-\frac{1}{\rho} \frac{\partial}{\partial z} \bar{\rho}\left(w-w_{T o}\right) q_{g}+\left(1-\delta_{3}\right) P_{R A C I}\left(T<T_{o}\right)+P_{G A C I}\left(T<T_{o}\right) \\
& +P_{G A C W}\left(T<T_{o}\right)+P_{G A C S}+\left(1-\delta_{4}\right) P_{S A C W}\left(T<T_{o}\right)+\left(1-\delta_{3}\right) P_{L A C R}\left(T<T_{o}\right)+P_{G A C R}\left(T<T_{o}\right) \\
& +P_{G F R}\left(T<T_{o}\right)+\left(1-\delta_{2}\right) P_{R A C S}\left(T<T_{o}\right)+\left(1-\delta_{4}\right) P_{W A C S}\left(T<T_{o}\right)-P_{G M L T}\left(T>T_{o}\right) \\
& +\left(1-\delta_{1}\right) P_{G D E P}\left(T<T_{o}\right)-P_{M L T G}\left(T>T_{o}\right)+\left(1-\delta_{2}\right) P_{S A C R}\left(T<T_{o}\right),
\end{aligned}
$$

where the microphysical processes in the terms of the right-hand side of (A1-A5) and corresponding schemes are listed in Table A1, and definitions and values of the other quantities can be found in Li et al. $(1999,2002 \mathrm{c})$.

To derive prognostic cloud scheme similar to Zhao and Carr (1997) in the frame of microphysics schemes in the cloud model, (A1) and (A3), and (A4) and (A5) are added, respectively,

$$
\begin{aligned}
& \frac{\partial\left(q_{c}+q_{i}\right)}{\partial t}=-\frac{\partial}{\partial x} u\left(q_{c}+q_{i}\right)-\frac{1}{\bar{\rho}} \frac{\partial}{\partial z} \bar{\rho} w\left(q_{c}+q_{i}\right)+P_{C N D}+P_{D E P}-P_{r}-P_{s g}-C\left(q_{c}, P_{s g}\right) \\
& \frac{\partial\left(q_{s}+q_{g}\right)}{\partial t}=-\frac{\partial}{\partial x} u\left(q_{s}+q_{g}\right)-\frac{1}{\rho} \frac{\partial}{\partial z} \bar{\rho}\left(w-w_{T V}\right)\left(q_{s}+q_{g}\right)-C\left(P_{r}, P_{s g}\right)-C_{m}\left(P_{r}, P_{s g}\right) \\
& +P_{s g}+C\left(q_{c}, P_{s g}\right)+\left(1-\delta_{1}\right) P_{S D E P}\left(T<T_{o}\right)+\left(1-\delta_{1}\right) P_{G D E P}\left(T<T_{o}\right)-P_{M L T S}\left(T>T_{o}\right) \\
& -P_{M L T G}\left(T>T_{o}\right)
\end{aligned}
$$

and the (A2) can be rewritten as

$$
\frac{\partial q_{r}}{\partial t}=-\frac{\partial\left(u q_{r}\right)}{\partial x}-\frac{1}{\bar{\rho}} \frac{\partial}{\partial z} \bar{\rho}\left(w-w_{T V}\right) q_{r}+P_{r}+C\left(P_{r}, P_{s g}\right)+C_{m}\left(P_{r}, P_{s g}\right)-P_{R E V P}
$$

where

$$
P_{r}=P_{S A C W}\left(T>T_{o}\right)+P_{R A U T}+P_{R A C W}+P_{G A C W}\left(T>T_{o}\right),
$$




$$
\begin{aligned}
& P_{s g}=P_{S A U T}\left(T<T_{o}\right)+P_{S A C I}\left(T<T_{o}\right)+P_{S F I}\left(T<T_{o}\right)+P_{R A C I}\left(T<T_{o}\right)+P_{G A C I}\left(T<T_{o}\right),(\mathrm{A} 9 \mathrm{~b}) \\
& C\left(q_{c}, P_{s g}\right)=P_{S A C W}\left(T<T_{o}\right)-P_{S F W}\left(T<T_{o}\right)-P_{G A C W}\left(T<T_{o}\right), \\
& C\left(P_{r}, P_{s g}\right)=P_{R A C S}\left(T>T_{o}\right)-P_{L A C R}\left(T<T_{o}\right)-P_{G A C R}\left(T<T_{o}\right)-P_{S A C R}\left(T<T_{o}\right)-P_{G F R}\left(T<T_{o}\right),
\end{aligned}
$$

$$
C_{m}\left(P_{r}, P_{s g}\right)=P_{S M L T}\left(T>T_{o}\right)+P_{G M T}\left(T>T_{o}\right)
$$

$\mathrm{P}_{\mathrm{r}}$ and $\mathrm{P}_{\mathrm{sg}}$ are the sums of microphysics processes directly linking to the growth of precipitating water $\left(\mathrm{q}_{\mathrm{r}}\right)$ and precipitating ice $\left(\mathrm{q}_{\mathrm{s}}\right.$ and $\left.\mathrm{q}_{\mathrm{g}}\right)$ respectively; $\mathrm{C}\left(\mathrm{q}_{\mathrm{c}}, \mathrm{P}_{\mathrm{sg}}\right)$ is conversion term between cloud water and precipitating ice; $C\left(\mathrm{P}_{\mathrm{r}}, \mathrm{P}_{\mathrm{sg}}\right)$ and $\mathrm{C}_{\mathrm{m}}\left(\mathrm{P}_{\mathrm{r}}, \mathrm{P}_{\mathrm{sg}}\right)$ are conversion terms between precipitating water and ice.

In addition to the assumption that the precipitating hydrometeors fall immediately out of clouds without any interaction with radiation, Zhao and Carr's (1997) prognostic cloud scheme excludes 14 terms (see italicized terms in Fig. A1; Also see Fig. 3 in ZC97 including $\mathrm{C}\left(\mathrm{q}_{\mathrm{c}}, \mathrm{P}_{\mathrm{sg}}\right), \mathrm{C}\left(\mathrm{P}_{\mathrm{r}}, \mathrm{P}_{\mathrm{sg}}\right), \mathrm{P}_{\mathrm{SDEP}}\left(\mathrm{T}<\mathrm{T}_{\mathrm{o}}\right), \mathrm{P}_{\mathrm{GDEP}}\left(\mathrm{T}<\mathrm{T}_{\mathrm{o}}\right), \mathrm{P}_{\mathrm{GACW}}\left(\mathrm{T}>\mathrm{T}_{\mathrm{o}}\right), \mathrm{P}_{\mathrm{SFI}}\left(\mathrm{T}<\mathrm{T}_{\mathrm{o}}\right)$, $\mathrm{P}_{\mathrm{GACl}}\left(\mathrm{T}<\mathrm{T}_{0}\right)$, and $\mathrm{P}_{\mathrm{RACI}}\left(\mathrm{T}<\mathrm{T}_{0}\right)$. Thus, (A6)-(A8) become

$$
\begin{aligned}
& \frac{\partial\left(q_{c}+q_{i}\right)}{\partial t}=-\frac{\partial}{\partial x} u\left(q_{c}+q_{i}\right)-\frac{1}{\bar{\rho}} \frac{\partial}{\partial z} \bar{\rho} w\left(q_{c}+q_{i}\right)+P_{C N D}+P_{D E P}-P_{r}-P_{s g}, \\
& \frac{\partial\left(q_{s}+q_{g}\right)}{\partial t}=-\frac{\partial}{\partial x} u\left(q_{s}+q_{g}\right)-\frac{1}{\bar{\rho}} \frac{\partial}{\partial z} \bar{\rho}\left(w-w_{T V}\right)\left(q_{s}+q_{g}\right)-C_{m}\left(P_{r}, P_{s g}\right)-P_{s g} \\
& -P_{M L T S}\left(T>T_{o}\right)-P_{M L T G}\left(T>T_{o}\right), \\
& \frac{\partial q_{r}}{\partial t}=-\frac{\partial\left(u q_{r}\right)}{\partial x}-\frac{1}{\rho} \frac{\partial}{\partial z} \bar{\rho}\left(w-w_{T V}\right) q_{r}+P_{r}+C_{m}\left(P_{r}, P_{s g}\right)-P_{R E V P},
\end{aligned}
$$

where

$$
P_{r}=P_{S A C W}\left(T>T_{0}\right)+P_{R A U T}+P_{R A C W},
$$




$$
\begin{aligned}
& P_{s g}=P_{S A U T}\left(T<T_{o}\right)+P_{S A C I}\left(T<T_{o}\right), \\
& C_{m}\left(P_{r}, P_{s g}\right)=P_{S M L T}\left(T>T_{o}\right)+P_{G M L T}\left(T>T_{o}\right) .
\end{aligned}
$$

Note that the prognostic equations of precipitating hydrometeors (raindrops, snow, and graupel) are kept here since the cloud schemes associated with the growth of nonprecipitating hydrometeors (cloud water and cloud ice) due to the conversions from precipitating hydrometeors (raindrops, snow, and graupel) are proportional to covariance between the mixing ratios of precipitation and non-precipitating hydrometeors in cloud microphysics parameterization schemes used in this study. Also note that separate prognostic equations for five hydrometeor spices are used in this study though (A10)(A13) are symbolically derived. 
Table A1 List of microphysical processes and their parameterization schemes in appendix. The schemes are Rutledge and Hobbs (1983, 1984; RH83, RH84), Lin et al. (1983, LFO), Tao et al. (1989, TSM), and Krueger et al. (1995, KFLC).

\begin{tabular}{|c|c|c|}
\hline Notation & Description & Scheme \\
\hline PMLTG $_{\text {MLT }}$ & Growth of vapor by evaporation of liquid from graupel surface & $\mathrm{RH} 84$ \\
\hline PMLTS & Growth of vapor by evaporation of melting snow & RH83 \\
\hline$P_{\text {REVP }}$ & Growth of vapor by evaporation of raindrops & RH83 \\
\hline$P_{I M L T}$ & Growth of cloud water by melting of cloud ice & RH83 \\
\hline $\mathrm{P}_{\mathrm{CND}}$ & $\begin{array}{l}\text { Growth of cloud water by the condensation of supersaturated } \\
\text { vapor }\end{array}$ & TSM \\
\hline $\mathrm{P}_{\mathrm{GMLT}}$ & Growth of raindrops by melting of graupel & RH84 \\
\hline $\mathbf{P}_{\text {SMLT }}$ & Growth of raindrops by melting of snow & RH83 \\
\hline $\mathrm{P}_{\mathrm{RACI}}$ & Growth of raindrops by the accretion of cloud ice & RH84 \\
\hline$P_{\text {RACW }}$ & Growth of raindrops by the collection of cloud water & RH83 \\
\hline $\mathrm{P}_{\mathrm{RACS}}$ & Growth of raindrops by the accretion of snow & RH84 \\
\hline$P_{\text {RAUT }}$ & Growth of raindrops by the autoconversion of cloud water & LFO \\
\hline $\mathrm{P}_{\mathrm{IDW}}$ & Growth of cloud ice by the deposition of cloud water & KFLC \\
\hline $\mathrm{P}_{\mathrm{IACR}}$ & Growth of cloud ice by the accretion of rain & RH84 \\
\hline $\mathrm{P}_{\text {IHOM }}$ & $\begin{array}{l}\text { Growth of cloud ice by the homogeneous freezing of cloud } \\
\text { water }\end{array}$ & \\
\hline$P_{D E P}$ & Growth of cloud ice by the deposition of supersaturated vapor & TSM \\
\hline P $_{\text {SAUT }}$ & Growth of snow by the conversion of cloud ice & RH83 \\
\hline $\mathrm{P}_{\mathrm{SACI}}$ & Growth of snow by the collection of cloud ice & RH83 \\
\hline $\mathrm{P}_{\mathrm{SACW}}$ & Growth of snow by the accretion of cloud water & RH83 \\
\hline $\mathrm{P}_{\text {SFW }}$ & Growth of snow by the deposition and riming of cloud water & KFLC \\
\hline$P_{\text {SFI }}$ & Depositional growth of snow from cloud ice & KFLC \\
\hline$P_{\text {SACR }}$ & Growth of snow by the accretion of raindrops & LFO \\
\hline $\mathrm{P}_{\text {SDEP }}$ & Growth of snow by the deposition of vapor & RH83 \\
\hline $\mathrm{P}_{\mathrm{GACI}}$ & Growth of graupel by the collection of cloud ice & RH84 \\
\hline $\mathrm{P}_{\mathrm{GACR}}$ & Growth of graupel by the accretion of raindrops & RH84 \\
\hline $\mathrm{P}_{\mathrm{GACS}}$ & Growth of graupel by the accretion of snow & RH84 \\
\hline$P_{\text {GACW }}$ & Growth of graupel by the accretion of cloud water & RH84 \\
\hline PWACS & Growth of graupel by the riming of snow & RH84 \\
\hline $\mathrm{P}_{\mathrm{GDEP}}$ & Growth of graupel by the deposition of vapor & RH84 \\
\hline$P_{\text {GFR }}$ & Growth of graupel by the freezing of raindrops & LFO \\
\hline
\end{tabular}




\section{References}

Golding BW (1990) The Meteorological Office mesoscale model. Meteor Mag 119: 8196

Grabowski WW, Wu X, Moncrieff MW (1996) Cloud-resolving model of tropical cloud systems during Phase III of GATE. Part I: Two-dimensional experiments. J Atmos Sci 53: 3684-3709

Grabowski WW, Wu X, Moncrieff MW, Hall WD (1998) Cloud-resolving model of tropical cloud systems during Phase III of GATE. Part II: Effects of resolution and the third spatial dimension. J Atmos Sci 55: 3264-3282

Grabowski WW, Wu X, Moncrieff MW (1999) Cloud-resolving model of tropical cloud systems during Phase III of GATE. Part III: Effects of cloud microphysics. J Atmos Sci 56: 2384-2402

Hsie EY, Farley RD, Orville HD (1980) Numerical simulation of ice phase convective cloud seeding. J Appl Meteor 19: 950-977

Johnson D, Tao WK, Simpson J, Sui CH (2004) A study of the response of deep tropical clouds to mesoscale processes: Part I: Modeling strategies and simulations of TOGA-COARE convective systems. J Atmos Sci 61 : in press

Koenig LR (1971) Numerical modeling of ice deposition. J Atmos Sci 28: 226-237

Krueger SK, Fu Q, Liou KN, Chin HNS (1995) Improvement of an ice-phase microphysics parameterization for use in numerical simulations of tropical convection. J Appl Meteor 34: 281-287

Li X, Sui CH, Lau KM, Chou MD (1999) Large-scale forcing and cloud-radiation interaction in the tropical deep convective regime. J Atmos Sci 56: 3028-3042 
Li X, Sui CH, Lau KM (2002a) Precipitation efficiency in the tropical deep convective regime: A 2-D cloud resolving modeling study. J Meteor Soc Japan 80: 205-212

Li X, Sui CH, Lau KM (2002b) Interactions between tropical convection and its environment: An energetics analysis of a 2D cloud resolving simulation. J Atmos

Sci 59: $1712-1722$

Li X, Sui CH, Lau KM (2002c) Dominant cloud microphysical processes in a tropical oceanic convective system: A 2-D cloud resolving modeling study. Mon Wea Rev 130: $2481-2491$

Lin YL, Farley RD, Orville HD (1983) Bulk parameterization of the snow field in a cloud model. J Climate Appl Meteor 22: 1065-1092

Liu Y, Zhang DL, Yau MK (1997) A multiscale numerical study of Hurricane Andrew (1992). Part I: Explicit simulation and Verification. Mon Wea Rev 125: 30733093

Lord SJ, Willoughby HE, Piotrowicz JM (1984) Role of a parameterized ice-phase microphysics in an axisymmetric, nonhydrostatic tropical cyclone model. J Atmos Sci 41: 2836-2848

Mannoji N (1995) An explicit cloud predicting scheme implemented in the Florida State University global spectral model and its impact. J Meteor Soc Japan 73: 993-1009

Orville HD, Kopp FJ (1977) Numerical simulation of the life history of a hailstorm. J Atmos Sci 34:1596-1618

Pudykiewicz J, Benoit R, Mailhot J (1992) Inclusion and verification of a predictive cloud-water scheme in a regional numerical weather prediction model. Mon Wea $\operatorname{Rev} 120: 612-626$ 
Rutledge SA, Hobbs PV (1983) The mesoscale and microscale structure and organization of clouds and precipitation in midlatitude cyclones. Part VIII: A model for the "seeder-feeder" process in warm-frontal rainbands. J Atmos Sci 40: 1185-1206

Rutledge SA, Hobbs PV (1984) The mesoscale and microscale structure and organization of clouds and precipitation in midlatitude cyclones. Part XII: A disgnostic modeling study of precipitation development in narrow cold-frontal rainbands. $\mathbf{J}$ Atmos Sci 41: 2949-2972

Smith RNB (1990) A scheme for predicting layer clouds and their water contents in a general circulation model. Quart J R Met Soc 116: 435-460

Soong ST, Ogura Y (1980) Response of tradewind cumuli to large-scale processes. J Atmos Sci 37: 2035-2050.

Soong ST, Tao WK (1980) Response of deep tropical cumulus clouds to Mesoscale processes. J Atmos Sci 37:2016-2034

Sui, CH, Lau KM, Tao WK, Simpson J (1994) The tropical water and energy cycles in a cumulus ensemble model. Part I: Equilibrium climate. J Atmos Sci 51: 711-728

Sui, CH, Li X, Lau KM (1998) Radiative-convective processes in simulated diurnal variations of tropical oceanic convection. J Atmos Sci 55:2345-2359

Sundqvist H (1978) A parameterization scheme for non-convective condensation including prediction of cloud water content. Quart J R Met Soc 104: 677-690

Sundqvist H, Berge E, Kristjansson JE (1989) Condensation and cloud studies with a mesoscale numerical weather prediction model. Mon Wea Rev 117: 1641-1657

Tao WK, Simpson J (1993) The Goddard Cumulus Ensemble model. Part I: Model description. Terr Atmos Oceanic Sci 4:35-72 
Tao WK, Simpson J, McCumber M (1989) An ice-water saturation adjustment. Mon Wea Rev 117: 231-235

Tiedtke M (1993) Representation of clouds in large-scale models. Mon Wea Rev 121: 3040-3061

Weller RA, Anderson SP (1996) Surface meteorology and air-sea fluxes in the western equatorial Pacific warm pool during TOGA COARE. J Climate 9:1959-1990

Weng F, Grody NC, Ferraro RR, Basist A, Forsyth D (1997) Cloud liquid water climatology from the Special Sensor Microwave/Imager. J Climate 10:1086-1098

Weng F, Grody NC (2000) Retrieval of ice cloud parameters using a microwave imaging radiometer. J Atmos Sci 57: 1069-1081

Weng F, Zhao L, Poe G, Ferraro RR, Li X, Grody NC (2003) AMSU cloud and precipitation algorithms. Radio Science 38(4): 8068, doi:10.1029/2002RS002679

Willoughby HE, Jin HL, Lord SJ, Piotrowicz JM (1984) Hurricane structure and evolution as simulated by an axisymmetric, non-hydrostatic numerical model. J Atmos Sci 41: 1169-1186

Wu X, Grabowski WW, Moncrieff MW (1998) Long-term evolution of cloud systems in TOGA COARE and their interactions with radiative and surface processes. Part I: Two-dimensional cloud-resolving model. J Atmos Sci 55: 2693-2714

Wu X, Hall WD, Grabowski WW, Moncrieff MW, Collins WD, Kiehl JT (1999) Longterm evolution of cloud systems in TOGA COARE and their interactions with radiative and surface processes. Part $\mathrm{H}$ : Effects of ice microphysics on cloudradiation interaction. J Atmos Sci 56: 3177-3195 
Xu KM, Randall DA (1996) Explicit simulation of cumulus ensembles with the GATE Phase III data: Comparison with observations. J Atmos Sci 53: 3710-3736

Zhang MH, Lin $\Omega$ (1997) Constrained variational analysis of sounding data based on column-integrated budgets of mass, heat, moisture, and momentum: Approach and application to ARM measurements. J Atmos Sci 54:1503-1524

Zhao Q, Carr FH (1997) A prognostic cloud scheme for operational NWP models. Mon Wea Rev 125: 1931-1953 


\section{Figure Captions}

Fig. 1 Temporal and vertical distribution of vertical velocity (a), zonal wind (b), and the time series of sea surface temperature (c) taken from TOGA COARE for 10-day period. Upward motion in (a) and westerly wind in (b) are shaded. Units of vertical velocity, zonal wind, and sea surface temperature are $\mathrm{cm} \mathrm{s}^{-1}, \mathrm{~m} \mathrm{~s}^{-1}$, and ${ }^{\circ} \mathrm{C}$, respectively.

Fig. 2 Time series of surface rain rate, Ps (a), vertically integrated mixing ratios of cloud water, [qc] (b), and cloud ice, [qi] (c) simulated in C (dashed) and C14 (solid). The plotting scales for [qi] are 0-0.4 $\mathrm{mm}$ for $\mathrm{C}$ and $0-3 \mathrm{~mm}$ for $\mathrm{C} 14$ respectively. Units of Ps, [qc], [qi] are $\mathrm{mm} \mathrm{h}^{-1}, \mathrm{~mm}, \mathrm{~mm}$.

Fig. 3 IWP versus LWP using the MSPPS data (a) and IWP (cloud ice) versus LWP (cloud water) using the GDAS data (b). Unit is mm.

Fig. 4 Temporal and vertical distribution of difference fields of (a) temperature $\left({ }^{\circ} \mathrm{C}\right)$, and (b) specific humidity $\left(\mathrm{gkg}^{-1}\right)$ for C14-C. Positive differences are shaded.

Fig. 5 Time series of cloud ice budgets simulated in (a) C and (b) $\mathrm{C} 14$ respectively. All terms are vertically integrated. Unit is $\mathrm{mm} \mathrm{h}^{-1}$.

Fig. 6 Same as in Fig. 4 except for CSFI-C.

Fig. 7 10-day mean vertically integrated cloud microphysics budgets simulated in (a) C and (b) CSFI. Units for cloud hydrometeors and conversions are $\mathrm{mm}$ and $\mathrm{mm} \mathrm{h}^{-1}$, respectively.

Fig. 8 Temporal and vertical distribution of (a) temperature differences between $\mathrm{CN}$ and $\mathrm{C}(\mathrm{CN}-\mathrm{C})$, and differences due to (b) condensational heating, (c) radiative 
heating, (d) convergence of vertical heat flux, and (e) vertical temperature advection. Unit is ${ }^{\circ} \mathrm{C}$. Positive differences are shaded.

Fig. 9 Temporal and vertical distribution of (a) differences of specific humidity between $\mathrm{CN}$ and $\mathrm{C}(\mathrm{CN}-\mathrm{C})$, and the differences due to $(\mathrm{b})$ condensation, (c) convergence of vertical moisture flux, and (d) vertical moisture advection. Unit is $\mathrm{gkg}^{-1}$. Positive differences are shaded.

Fig. Al Diagram of microphysical processes in the cloud resolving model. The terms in italics are excluded in the experiment $\mathrm{C} 14$. 

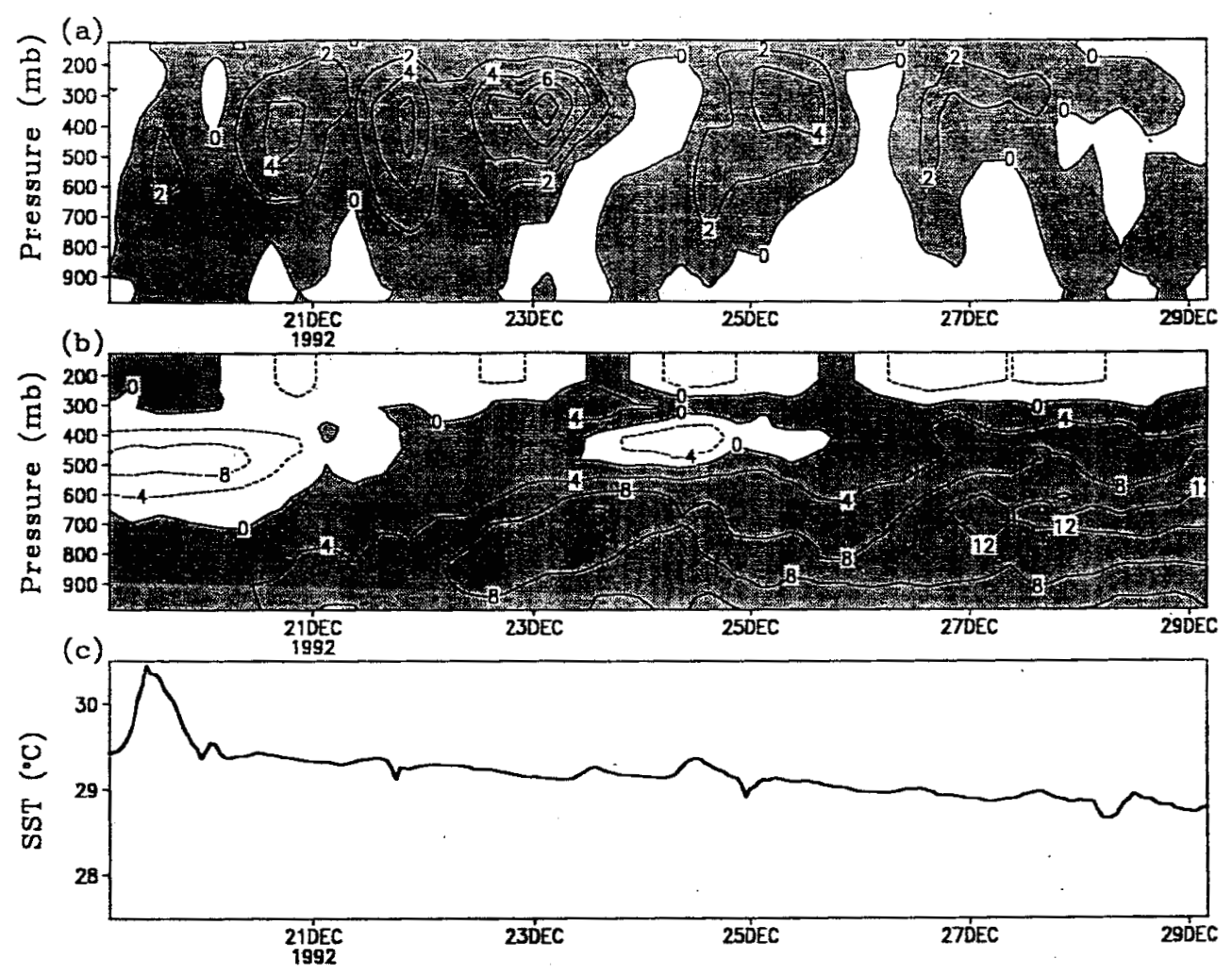

Fig. 1 Temporal and vertical distribution of vertical velocity (a), zonal wind (b), and the time series of sea surface temperature (c) taken from TOGA COARE for 10-day period. Upward motion in (a) and westerly wind in (b) are shaded. Units of vertical velocity, zonal wind, and sea surface temperature are $\mathrm{cm} \mathrm{s}^{-1}, \mathrm{~m} \mathrm{~s}^{-1}$, and ${ }^{\circ} \mathrm{C}$, respectively. 

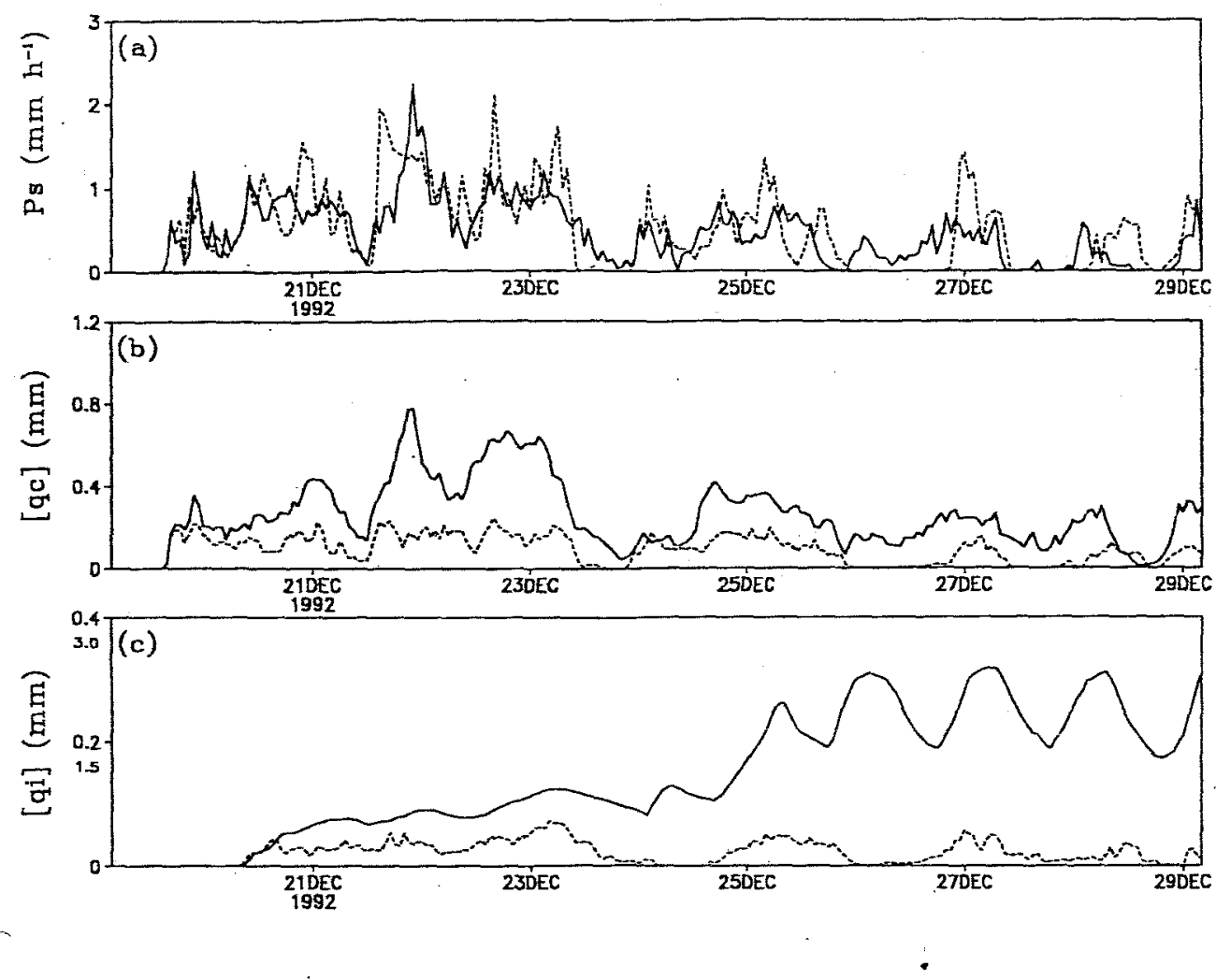

Fig. 2 Time series of surface rain rate, Ps (a), vertically integrated mixing ratios of cloud water, [qc] (b), and cloud ice, [qi] (c) simulated in C (dashed) and C14 (solid). The plotting scales for [qi] are 0-0.4 $\mathrm{mm}$ for $\mathrm{C}$ and $0-3 \mathrm{~mm}$ for C14 respectively. Units of Ps, [qc], [qi] are $\mathrm{mm} \mathrm{h}^{-1}, \mathrm{~mm}, \mathrm{~mm}$. 

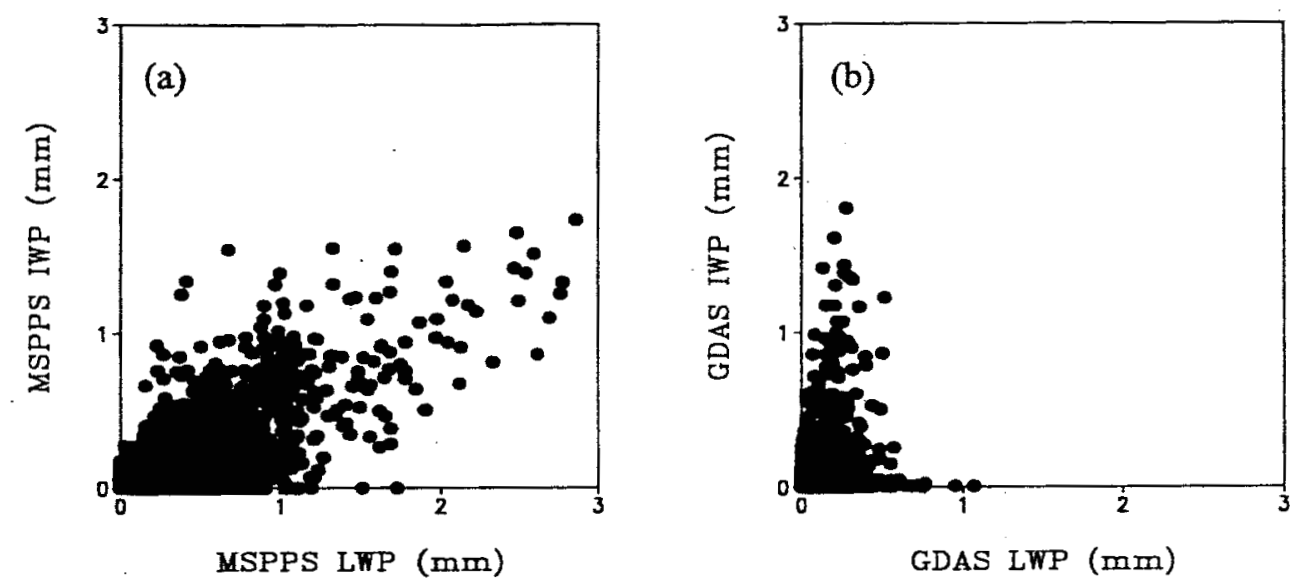

Fig. 3 IWP versus LWP using the MSPPS data (a) and IWP (cloud ice) versus LWP (cloud water) using the GDAS data (b). Unit is mm. 

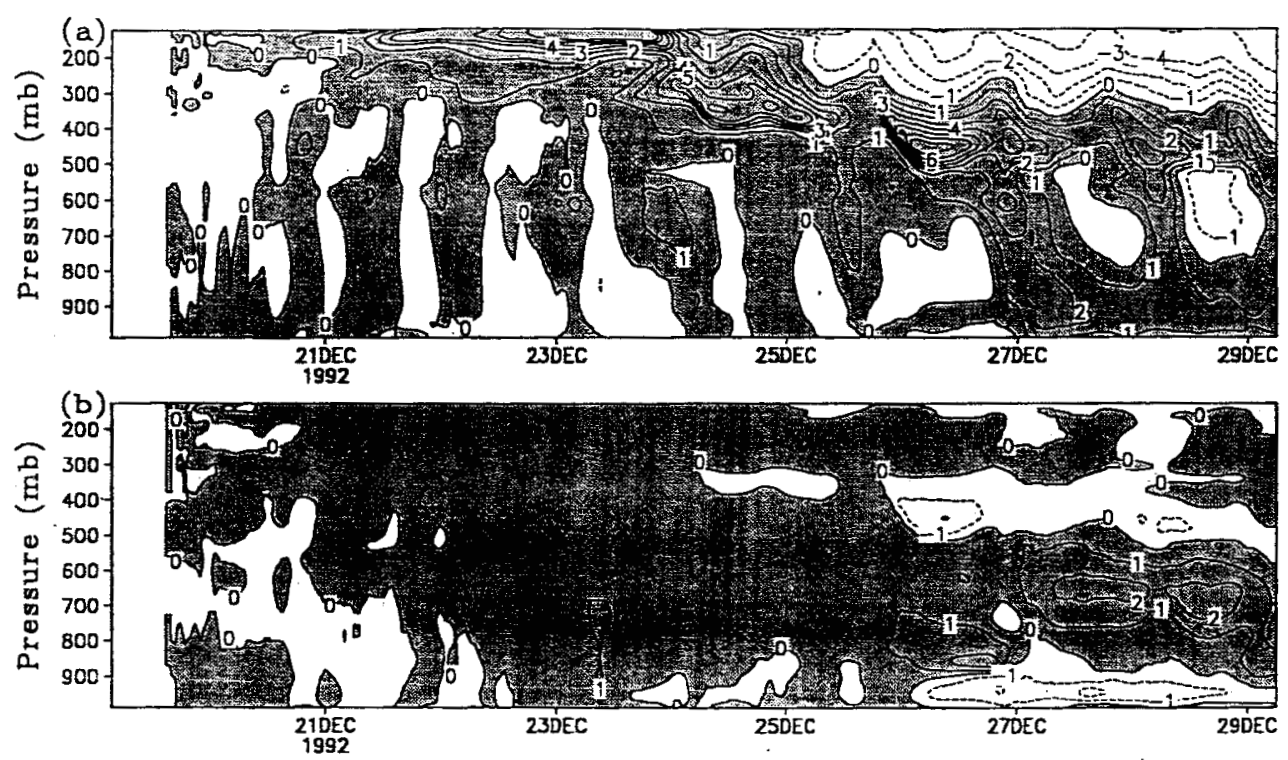

Fig. 4 Temporal and vertical distribution of difference fields of (a) temperature $\left({ }^{\circ} \mathrm{C}\right)$ and (b) specific humidity $\left(\mathrm{gkg}^{-1}\right)$ for C14-C. Positive differences are shaded. 

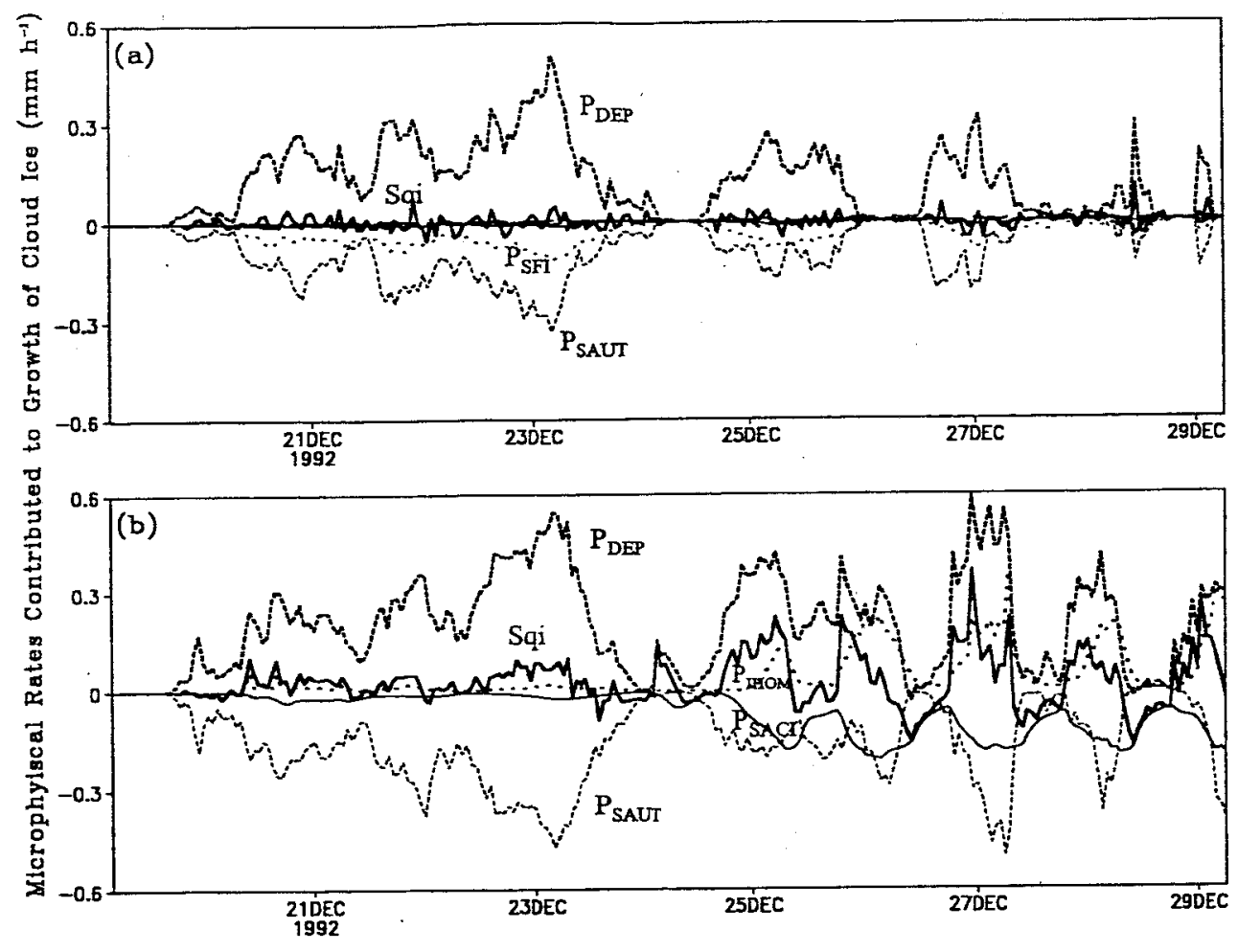

Fig. 5 Time series of cloud ice budgets simulated in (a) C and (b) C14 respectively. All terms are vertically integrated. Unit is $\mathrm{mm} \mathrm{h}^{-1}$. 

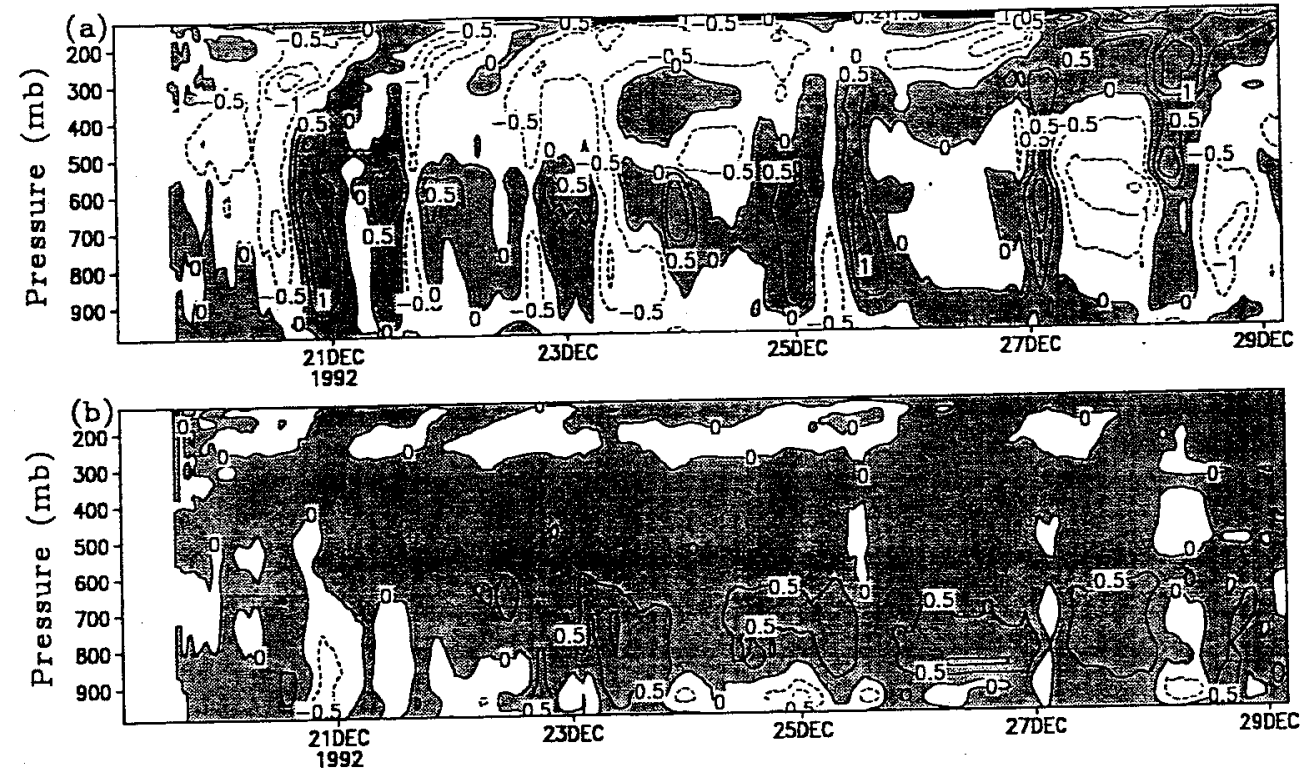

Fig. 6 Same as in Fig. 4 except for CSFI-C. 
(a)

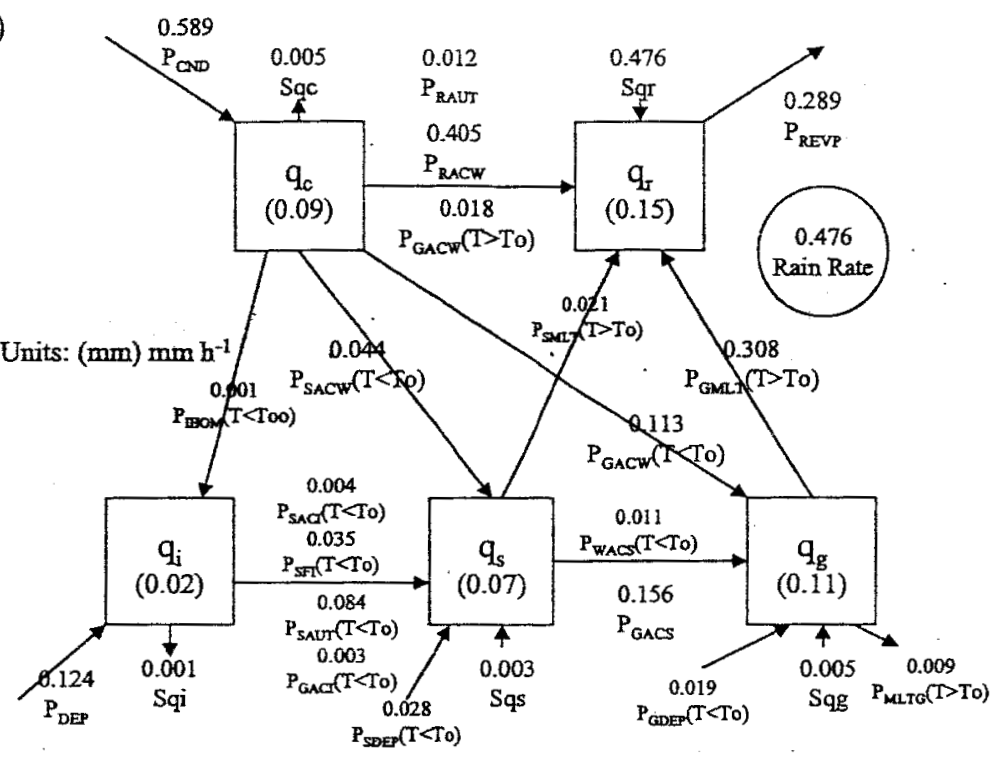

(b)

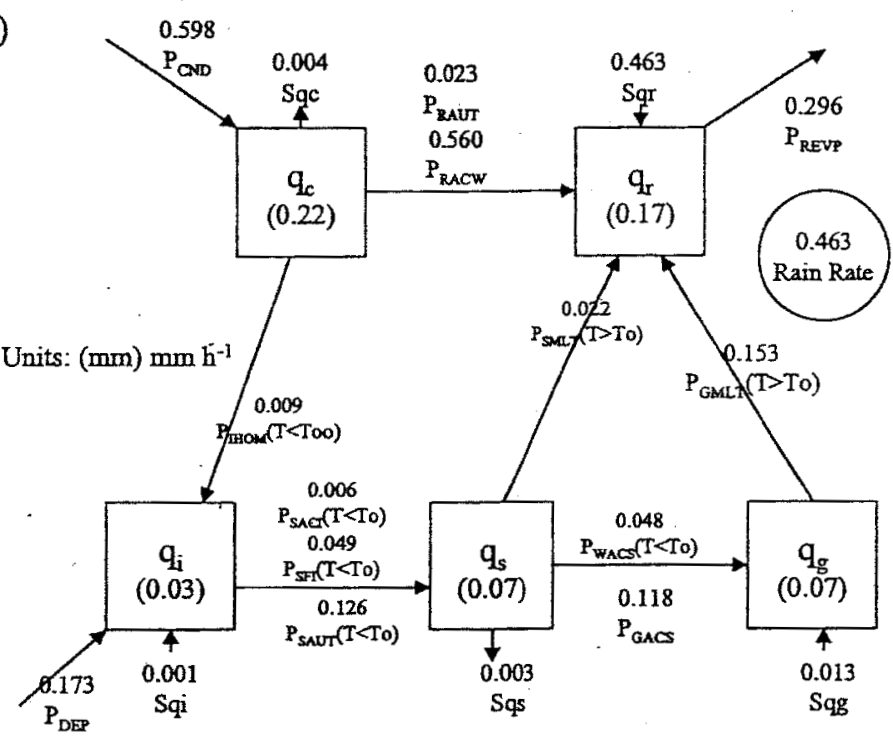

Fig. 7 10-day mean vertically integrated cloud microphysics budgets simulated in (a) C and (b) CSFI. Units for cloud hydrometeors and conversions are $\mathrm{mm}$ and $\mathrm{mm} \mathrm{h} \mathrm{h}^{-1}$, respectively. 


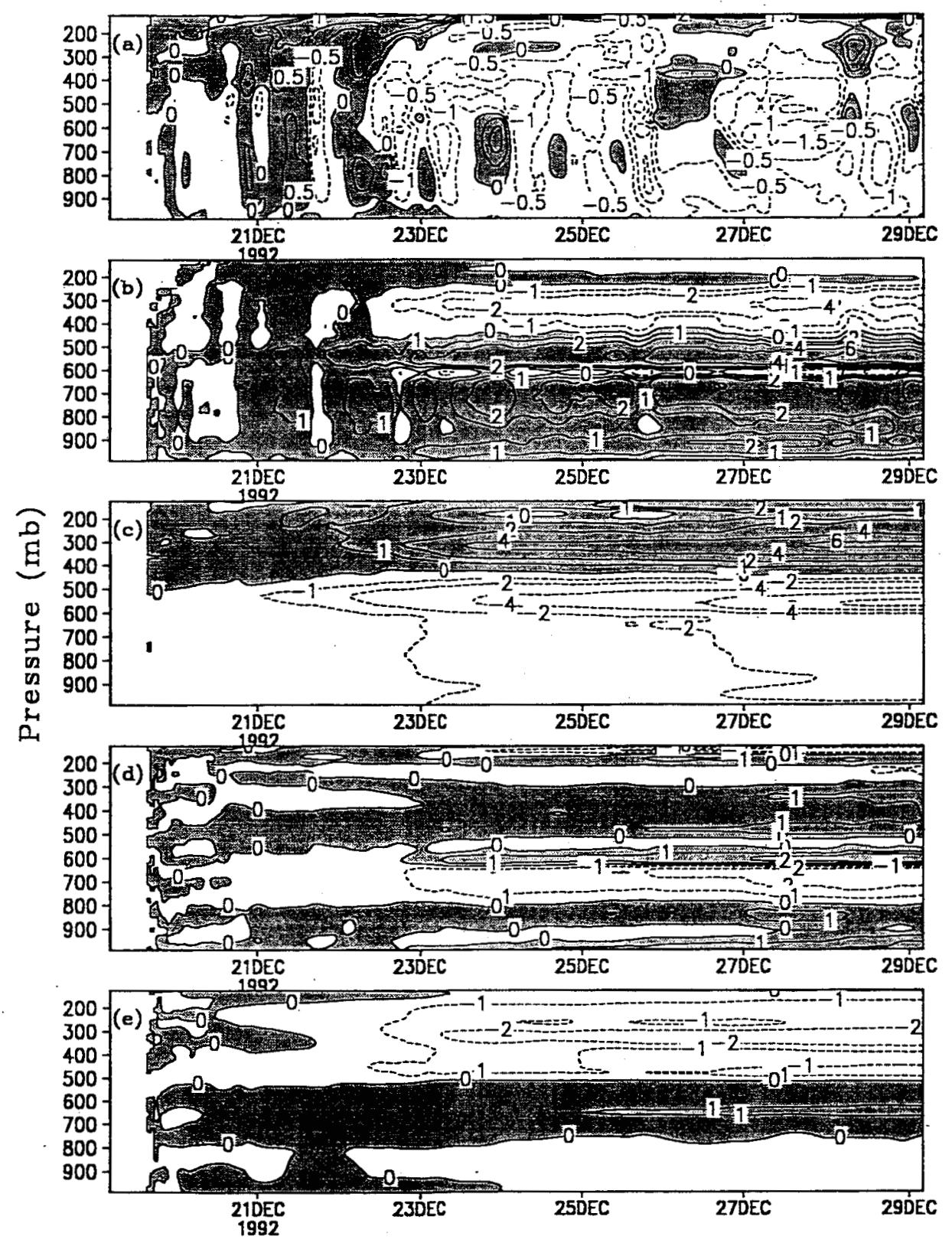

Fig. 8 Temporal and vertical distribution of (a) temperature differences between $\mathrm{CN}$ and $\mathrm{C}(\mathrm{CN}-\mathrm{C})$, and differences due to (b) condensational heating, (c) radiative heating, (d) convergence of vertical heat flux, and (e) vertical temperature advection. Unit is ${ }^{\circ} \mathrm{C}$. Positive differences are shaded. 


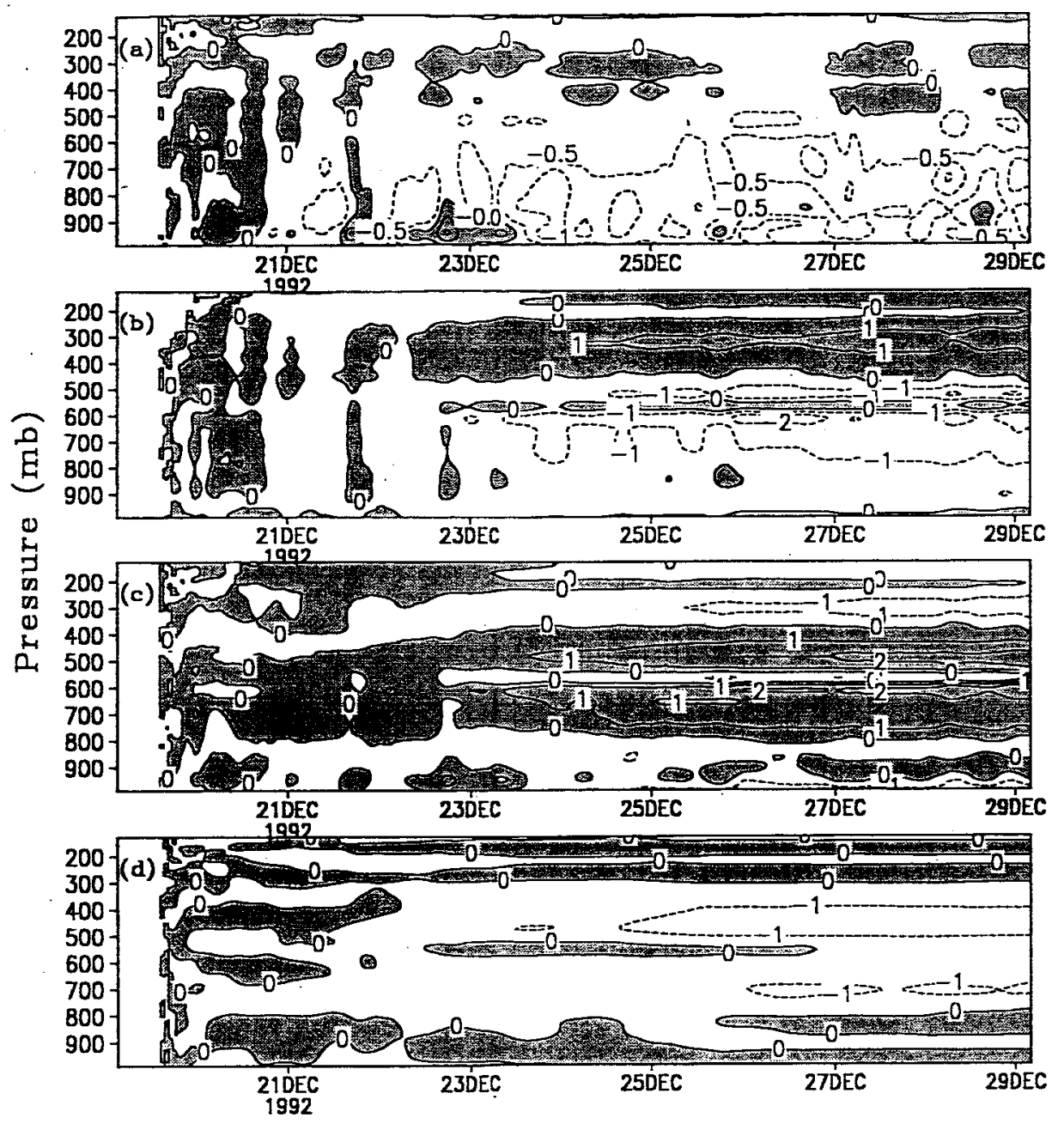

Fig. 9 Temporal and vertical distribution of (a) differences of specific humidity between $\mathrm{CN}$ and $\mathrm{C}(\mathrm{CN}-\mathrm{C})$, and the differences due to (b) condensation, (c) convergence of vertical moisture flux, and (d) vertical moisture advection. Unit is $\mathrm{gkg}^{-1}$. Positive differences are shaded. 


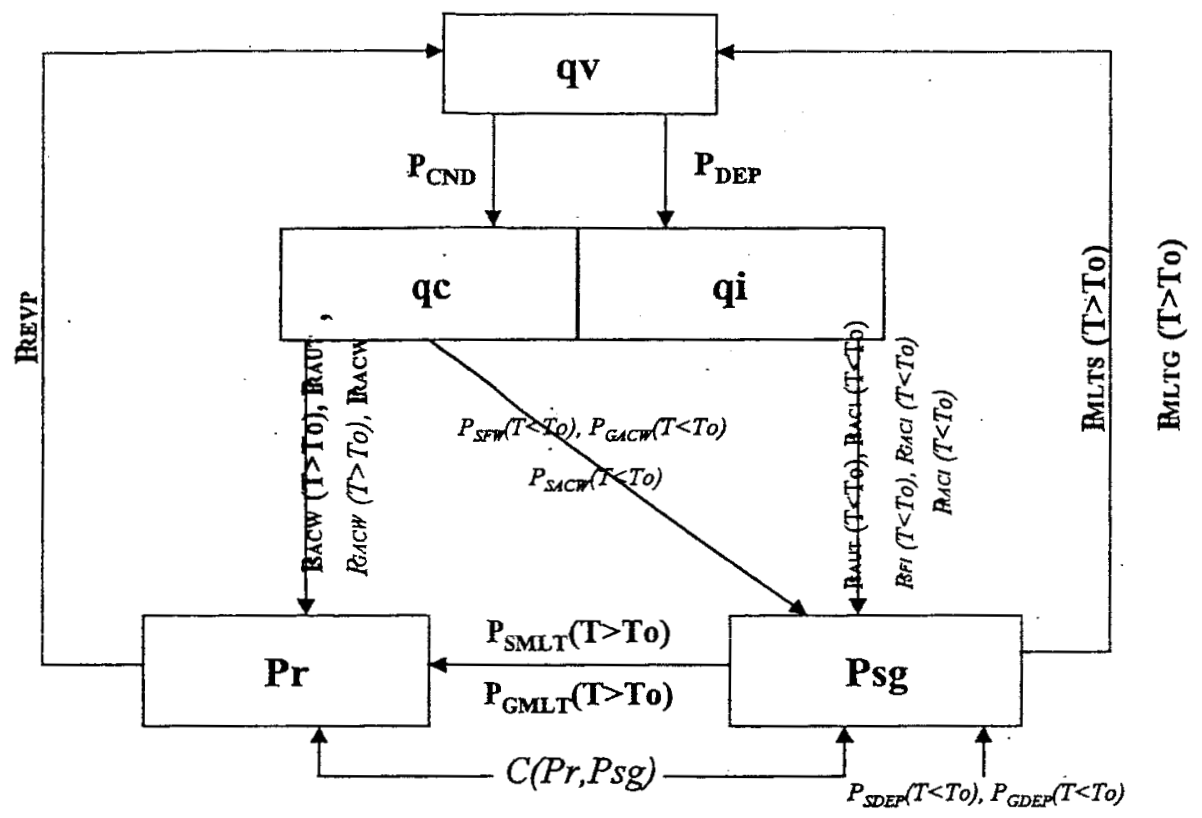

Fig. A1 Diagram of microphysical processes in the cloud resolving model. The terms in italics are excluded in the experiment $\mathrm{C} 14$. 


\title{
Tropical Convective Responses to Microphysical and Radiative Processes: A Sensitivity Study With a 2D Cloud Resolving Model
}

\author{
Xiaofan Li, C.-H. Sui, K.-M. Lau, W.-K. Tao \\ Meteorology and Atmospheric Physics
}

\section{Popular Summary}

Prognostic cloud schemes are increasingly used in weather and climate models in order to better treat cloud-radiation processes. Simplifications are often made in such schemes for computational efficiency, like the scheme being used in the National Centers for Environment Prediction models that excludes some microphysical processes and precipitation-radiation interaction. In this study, sensitivity tests with a $2 \mathrm{D}$ cloud resolving model are carried out to examine effects of the excluded microphysical processes and precipitation-radiation interaction on tropical thermodynamics and cloud properties. The model is integrated for 10 days with the imposed vertical velocity derived from the Tropical Ocean Global Atmosphere Coupled Ocean-Atmosphere Response Experiment. The experiment excluding the depositional growth of snow from cloud ice shows anomalous growth of cloud ice and more than $20 \%$ increase of fractional cloud cover, indicating that the lack of the depositional snow growth causes unrealistically large mixing ratio of cloud ice. The experiment excluding the precipitation-radiation interaction displays a significant cooling and drying bias. The analysis of heat and moisture budgets shows that the simulation without the interaction produces more stable upper troposphere and more unstable mid and lower troposphere than does the simulation with the interaction. Thus, the suppressed growth of ice clouds in upper troposphere and stronger radiative cooling in mid and lower troposphere are responsible for the cooling bias, and less evaporation of rain associated with the large-scale subsidence induces the drying in mid and lower troposphere. 